\title{
Applications and Issues of Unmanned Aerial Systems in the Construction Industry
}

\author{
Ibrahim Mosly \\ College of Engineering-Rabigh Branch, Department of Civil Engineering, King Abdulaziz University, Jeddah, Saudi Arabia
}

\begin{abstract}
The adoption of innovative technologies in the construction industry is necessary for the industry development. Such technologies can help in reducing the time needed to accomplish tasks, increase work quality, improve safety standards, and lower expenses. Unmanned aerial systems (UAS) have various applications on construction sites. They provide a bird's eye view for supervising construction site personnel as well as providing live feedback on actions taking place on-site. Given the high potential of UAS use in the construction industry and their recent wide usage, this study and literature review aims to summarize the current applications of UAS on construction sites. Furthermore, it will also identify the issues resulting from UAS use in the construction industry. The findings will enhance understanding of the implementation of UAS in the construction industry.
\end{abstract}

Keywords Applications, Issues, Unmanned aerial systems, Construction industry

\section{Introduction}

Proven innovative technologies are very beneficial to any industry, as they are mainly developed to increase work efficiency. The implementation of such technologies can result in faster task-completion time, higher work quality, enhanced safety standards, and cost reduction. Unfortunately, the rate of adoption of innovative technologies by the construction industry is far behind that of several other industries [1]. Technology use on construction sites poses a challenge for construction management [2]. This is due to several constraints and barriers as well as the dynamic nature of construction sites.

Unmanned aerial systems (UAS), also referred to as unmanned aerial vehicles or drones, are innovative technology that can be very useful in different applications in the construction industry. The term "UAS" is being increasingly used to accommodate the broad range of technological applications [3]. Today, several UAS are controlled by Smartphone devices, linked by Wi-Fi networks, and their locations can be pinpointed via global positioning systems [4]. UAS can be used to perform data collection and processing; they can also be operated with or without a pilot [5]. The following tools can be mounted on UAS: cameras, infrared, radar, and communication devices [5]. Live data transfer with control stations is possible with most types of UAS; certain UAS may have data storage

* Corresponding author:

ikmosly@kau.edu.sa (Ibrahim Mosly)

Published online at http://journal.sapub.org/ijcem

Copyright (C) 2017 Scientific \& Academic Publishing. All Rights Reserved options [5].

The earliest adoption of UAS was for military applications [6, 7]. However, the current situation has changed, and UAS are now involved in civilian applications. An increasing number of researchers have explored UAS use in construction applications [8]. This can be seen in the recent growing number of research publications on UAS use on construction sites. The present interest in UAS use for civilian and commercial purposes is due to the broad range of applications along with savings in labor, time, and cost, and even enhanced performance [3]. UAS can perform in a number of construction applications, replacing traditionally used techniques [9]. Moreover, UAS can assist in conducting construction applications with an enhanced and faster approach [9]. For example, UAS can provide geometric information on actual construction site conditions frequently and with low error rates [10]. UAS are also used for transportation and construction site monitoring [2]. Although there is potential for using UAS on construction sites, the construction industry has been slow to adopt it [11]. Furthermore, there is a demand for further exploration to understand how UAS can be used in the various construction management activities [12]. Operational procedures for effective UAS use, specifically for construction site safety monitoring, still require development [2]. Thus, it is important to study the issues related to UAS use in the construction industry. The literature on research on UAS applications in civil engineering are scant [6]. There is a need for scientific exploration and evaluation of UAS performance in the construction environment [6]. This study was conducted with the aim of summarizing the applications and issues of 
UAS use in the construction industry, which will aid in recognizing several areas for improvement and future research.

\section{Methodology}

This study was conducted to identify the applications and issues of UAS use in the construction industry through a systematic literature review. The findings will aid understanding and summarizing of the latest research on the integration of UAS with the construction industry. Here, focus was given on the most recently identified applications and issues of UAS use in the construction industry. The relevant literature was obtained via Google Scholar, Science Direct, the Taylor \& Francis publishing group, the American Society of Civil Engineers, and Springer publications. The search terms included "construction", "drones", "UAS", "unmanned aerial vehicles", "applications", "issues", "problems", "risks", and "barriers". Only articles that discussed the topic or those that covered an area related to the topic were selected and cited. In this study, 33 articles were obtained, which included journal articles, conference papers, magazine articles, and reports. One article was published in 2012, and the other 32 articles had been published between 2014 and 2017. This shows that the research topic is a relatively new concept and that more research is warranted. Two research questions were investigated in this study, these are:

1. What are the applications of UAS in the construction industry?

2. What are the issues in UAS use in the construction industry?

\section{Applications of UAS in the Construction Industry}

The use of UAS in the construction industry is a relatively new concept, and industry stakeholders are still discovering its applications. This section will answer the first research question, i.e., What are the applications of UAS in the construction industry? Examination of the literature identified nine main applications of UAS in the construction industry (see Table 1). Of the nine identified applications, five were mentioned in at least 12 articles each, and included monitor construction activities, site surveying, aerial photography and surveillance, visual inspection of hard-to-reach locations, and safety inspection. The other four applications were not widely discussed in the literature: interaction with workers, quantity take-off and estimation, and construction site security were mentioned in two articles each, while defect and damage detection was mentioned in a single article. The number of articles that mention an application does not indicate the application's importance, but rather the more widely used application of UAS in the construction industry that drew the interest of researchers.
Table 1. Applications of UAS in the construction industry

\begin{tabular}{|l|l|}
\hline \multicolumn{1}{|c|}{ Application } & \multicolumn{1}{|c|}{ Reference } \\
\hline Monitor construction activities & {$[1,3-5,7,9,13-21]$} \\
\hline Site surveying & {$[3,4,6,11,15,16,19,21-28]$} \\
\hline $\begin{array}{l}\text { Aerial photography and } \\
\text { surveillance }\end{array}$ & $\begin{array}{l}{[3,5-9,14,16,17,19,21-23,} \\
29,30]\end{array}$ \\
\hline $\begin{array}{l}\text { Visual inspection of hard-to-reach } \\
\text { locations }\end{array}$ & $\begin{array}{l}{[3,5,8,9,13,14,16,17,19,} \\
21,23,31]\end{array}$ \\
\hline Safety inspection & {$[1-3,5,13,14,16,17,19,25$,} \\
\hline Interaction with workers & $31,32]$ \\
\hline Quantity take-off and estimation & {$[1,14]$} \\
\hline Construction site security & {$[9,19]$} \\
\hline Defect and damage detection & {$[9,23]$} \\
\hline
\end{tabular}

UAS are changing the manner in which construction companies do business [4], and UAS can be integrated into construction tasks in several ways [11]. Generally, the UAS is used to provide a bird's eye view for construction site supervisory personnel. In the fields of architecture, engineering, and construction, UAS has become an emerging research topic for three-dimensional mapping [22]. Three-dimensional mapping enables the monitoring of site progress, surveying and measuring tasks, and the performance of quality control [22]. There has been exponential growth in UAS use in visual construction monitoring and in the visual operation of many types of buildings and civil infrastructure systems [16]. For example, UAS can be used to create interactive maps of buildings and sites by conducting site surveys and constructing three-dimensional models of these locations [11, 15]. Furthermore, for tasks that include the mapping of wide areas such as excavations, UAS have been accepted as both dependable and efficient devices [15]. Contractors are increasingly monitoring their construction activities using UAS [4]. This is because UAS offer live streaming on job progress and can assist in identifying potential hazards or quality concerns, as well as other helpful information in a quick and cost-saving manner [4]. UAS are also helpful for monitoring large construction sites [4]. A larger construction site becomes more difficult to monitor and it is here that UAS can play a role; UAS can survey and map landfills [4]. Several studies on UAS use for project progress monitoring have reported the potential of using UAS in such an application [5, 7, 15].

Aerial photography inside and outside construction sites is presently the most common UAS application [9]. UAS equipment capabilities have advanced significantly, providing enhanced high-resolution imagery from diverse angles while being both cost-effective and efficient [7]. Typically, construction sites install fixed surveillance camera systems [13]. However, as construction sites are typically very busy, it becomes impossible to view the fixed camera range fully without a structural element, equipment, or on-site material blocking it [13]. In such situations, UAS can maneuver around any obstacles present at a construction 
site and cover all required locations. Thus, UAS provide aerial views from a variety of elevations and angles [9]. Consequently, UAS can be considered more flexible compared to fixed cameras [9]. In addition, UAS can be piloted manually (controlled by a pilot) or autonomously (predefined path with no pilot) [22].

UAS can be used to regularly survey construction sites, monitor current activities, generate safety documents, and examine structures, in particular, the areas that are hard to reach [16]. UAS can access difficult locations in construction sites and allow safety managers to interact with workers during critical situations [14]. Researchers view UAS as a low-cost aerial photography tool for construction inspection, specifically for locations that are hazardous or unfeasible, such as roofs and building façades [5]. Using UAS for inspecting construction and infrastructure guarantees appropriate performance and user safety against structure collapse, and at the same time, prevents worker exposure to injury [3]. Obscure locations such as the exterior building envelope or locations with major personnel safety issues are frequent constraints for inspectors conducting visual surveillance [9]; UAS make it possible for inspectors to view these locations from a safe distance [9]. For example, in the case of structural fire on a roof, a UAS will allow the inspector to safely view still images and video of the damaged areas and perform an accurate assessment [9]. Moreover, UAS mounted with thermogtaphic cameras can capture heat flow, which allows the mapping of roof insulation or pipe insulation issues [9]. Furthermore, the size of a UAS allows it to access the interior of construction projects, which is not possible by helicopter due to size restrictions and the limited ability to access open venues such as stadiums [9]. A UAS would provide safety managers live contact with workers through a communication tool, including video and voice transmitters [1,17]. This is highly beneficial, as it allows safety managers to oversee the construction site and provide workers with live feedback [1]. Another application of UAS is conducting roof estimates. Some contractors use UAS for estimating roofs, as some roofs are difficult to walk on and may be easily damaged, such as those made with slate or clay tiles [9].

Construction workforces are exposed to accidents that lead to financial losses, disabilities, and casualties [1]. UAS can enhance construction practices and facilitate safety inspections of the jobsite [1]. Furthermore, they can instantly alert operators to accidents and assist safety managers in identifying the accident location and injured workers [17]. UAS can be used as an effective and cost-saving safety inspection tool for high-rise structures [31]. This is because high-rise structural inspection is very dangerous and is considered time-consuming, costly, and difficult to diagnose [31]. Visual data collected by UAS can enhance the safety inspection of a site through improved visualization of working situations [2]. Moreover, night security shifts can use UAS by flying them regularly over the site and detecting heat signatures via thermographic cameras, which can assist in detecting hiding burglars [9].

\section{Issues in UAS Use in the Construction Industry}

Equations Similar to any technology, UAS use on construction sites has its issues. This section will answer the second research question, what are the issues in UAS use in the construction industry? Examination of the obtained literature identifies 10 issues in UAS use in the construction industry (see Table 2). The most commonly mentioned issues were accidents resulting in deaths, disabling injuries, and property damage, and weather condition constraints, which were discussed in eight articles each. These issues were followed by the issue of laws and regulation restrictions, which was discussed in six articles. Subsequently, battery life and limited flight time was mentioned in five articles. Next, four articles mentioned privacy concerns. The following three issues were mentioned in three articles each: must be operated by a competent person, labor and work distraction, and communication loss/interference/low-quality images. Finally, two issues were mentioned in one article each: does not function well at extreme temperatures, and analysis of large database of visual assets.

Table 2. Issues in UAS use in the construction industry

\begin{tabular}{|l|l|}
\hline \multicolumn{1}{|c|}{ Issue } & \multicolumn{1}{c|}{ Reference } \\
\hline $\begin{array}{l}\text { Accidents resulting in deaths, disabling } \\
\text { injuries and property damages }\end{array}$ & $\begin{array}{l}{[1,3,5,9,12,15,23,} \\
29]\end{array}$ \\
\hline Weather condition constraints & $\begin{array}{l}{[2,8,9,15,22,27,29,} \\
33]\end{array}$ \\
\hline Laws and regulation restrictions & {$[2,5,11,19,23,33]$} \\
\hline Battery life and limited flight time & {$[6,13,14,21,33]$} \\
\hline Privacy concerns & {$[3,5,12,23]$} \\
\hline Must be operated by a competent person & {$[2,9,12]$} \\
\hline Labor and work distraction & {$[1,5,12]$} \\
\hline $\begin{array}{l}\text { Communication } \\
\text { loss/interference/low-quality images }\end{array}$ & {$[21,22,29]$} \\
\hline $\begin{array}{l}\text { Does not function well at extreme } \\
\text { temperatures }\end{array}$ & {$[9]$} \\
\hline Analysis of large database of visual assets & {$[2]$} \\
\hline
\end{tabular}

Any innovative technology would typically encounter a number of issues, and it is necessary to identify these issues and try to find the means to avoid them. Further research is needed on issues related to UAS use, including regulatory impact, construction personnel learning curve impact, privacy concerns, and jobsite safety issues [5]. Uncertainty regarding the laws and regulations of UAS use represent a barrier to UAS integration into construction projects [11]. Unclear or changing laws and regulations might also drive users away from adopting UAS. Another issue in UAS implementation on construction sites is the need for well-trained pilots. To conduct an effective safety inspection flight, it is necessary for the pilot, observer, and project personnel to know their flight objective [2]. An effective UAS operation requires experienced personnel to fly it [9]. 
Meteorological factors and pilot training are barriers that affect UAS use for safety inspection [12]. The literature also mentioned the issue of having too much visual data to analyze. A study that tested UAS for safety inspection found difficulty in analyzing the large amount of visual data collected in a single visit [2]. Moreover, worker distraction by the operation of a UAS at a construction site represents an issue [1]. This is why it is important to provide project staff with training and communication about UAS operation prior to its commencement, including information on the technology and objectives [5].

Although not frequent, the exposure of the pilot and others to UAS operational accidents may result in death and disabling injury [9]. A mechanical malfunction or loss of power can cause a UAS to rapidly fall to the ground with little or no warming [9]. Thus, the operator should avoid flying the UAS over areas where people are working whenever possible [9]. Generally, UAS do not function well at extremely hot or cold temperatures [9], and thus might cause an accident. Extremely cold temperatures can cause problems with the mechanical controls of UAS, and their batteries lose their effectiveness [9]. Another issue in UAS operation is the limited flight time. Therefore, the limitations of UAS use include restricted flight time and battery life [6, 13]. UAS flight time is approximately 30 minutes and is restricted by the battery capacity [13].

Weather conditions are a challenge for UAS operation on construction sites. UAS are incapable of functioning at high wind speeds $[2,9,22]$. The case is the same for rainy days [2, 22]. Furthermore, these weather conditions can affect the quality of the visual data collected. For example, sunlight and time of flight may affect image specifications [22]. Moreover, shadows and glare from reflective surfaces can affect three-dimensional mapping conducted by UAS [22].

Magnetic sources around a UAS may result in communication interference, which is due to the electrical sensors in the UAS, such as the gyroscope or compass, being affected [22]. Thus, the UAS takeoff location and flight path should be away from large metal objects or reinforced concrete structures [22]. Furthermore, loss of connection between the UAS and controller has occurred a number of times during UAS testing, resulting in missing images and consequently affecting three-dimensional mapping [22].

\section{Conclusions}

The use of new innovative technologies such as UAS in the construction industry is greatly needed for developing various aspects of the industry, such as safety. As UAS use at construction sites is relatively new, a number of issues might arise, affecting the on-site operation. This illustrates the importance of conducting in-depth research on UAS use in the construction industry. The present study examined 33 articles from the available literature on UAS applications and issues in UAS use in the construction industry and summarized them. Moreover, nine applications and 10 issues were identified in UAS use in the construction industry. Future research might include investigating areas that increase the applications of UAS in the construction industry; furthermore, it may cover the methods and means of reducing issues in UAS use in the construction industry.

\section{REFERENCES}

[1] Irizarry, J., M. Gheisari, and B. Walker, Usability Assessment of Drone Technology as Safety Inspection Tools. Journal of Information Technology in Construction, 2012. 17 (September): p. 194-212.

[2] Melo, R., et al., Applicability of unmanned aerial system (UAS) for safety inspection on construction sites. Safety Science, 2017. 98(October): p. 174-185.

[3] Schreiber, L. and E. Ostiari, Game of drones: do civilian applications harbour opportunities for sustainable development? 2014, Mirova: Paris, France.

[4] Babel, J., Up in the Air: The emerging issue of drones in the construction industry. 2015, XL Catlin: NY. USA. p. 1-3.

[5] Irizarry, J. and D. Costa, Exploratory Study of Potential Applications of Unmanned Aerial Systems for Construction Management Tasks. Journal of Management in Engineering, 2016. 32(3): p. 1-10.

[6] Siebert, S. and J. Teizer, Mobile 3D mapping for surveying earthwork projects using an Unmanned Aerial Vehicle (UAV) system. Automation in Construction, 2014. 41(May): p. 1-14.

[7] Vacanas, Y., et al., The combined use of Building Information Modelling (BIM) and Unmanned Aerial Vehicle (UAV) Technologies for the 3D illustration of the progress of works in infrastructure construction projects, in Fourth International Conference on Remote Sensing and Geoinformation of the Environment 2016: Cyprus. p. 1-8.

[8] Fleming, K., et al., Novel Technologies for Deep-Excavation Digital Construction Records. Practice Periodical on Structural Design and Construction, 2016. 21(4): p. 1-10.

[9] Opfer, N. and D. Shields, Unmanned Aerial Vehicle Applications and Issues for Construction, in 121st ASEE Annual Conference \& Exposition. 2014: Indiana, USA. p. $1-15$.

[10] Wang, J., S. Zhang, and J. Teizer, Geotechnical and safety protective equipment planning using range point cloud data and rule checking in building information modeling. Automation in Construction, 2015. 49(January): p. 250-261.

[11] Mickel, C., Despite Clear Benefits the Construction Industry is Slow to Integrate Unmanned Aerial Vehicles into Projects, in Under Construction 2016, American Bar Association Forum on Construction Law. p. 1-8.

[12] D Costa, et al., Evaluating the Performance of Unmanned Aerial Vehicles for Safety Monitoring, in 24th Ann. Conf. of the Int'l. Group for Lean Construction. 2016: Boston, USA. p. 23-32.

[13] Fang, Y., et al., A Point Cloud-Vision Hybrid Approach for 3D Location Tracking of Mobile Construction Assets, in 33rd 
International Symposium on Automation and Robotics in Construction. 2016: Auburn, USA. p. 1-8.

[14] Hubbard, B., et al., Feasibility Study of UAV use for RFID Material Tracking on Construction Sites, in 51st ASC Annual International Conference. 2015: Texas, USA. p. 1-8.

[15] Freimuth, H. and M. König, Generation of Waypoints for Uav-Assisted Progress Monitoring and Acceptance of Construction Work, in 15th International Conference on Construction Applications of Virtual Reality. 2015: Alberta, Canda.

[16] Ham, Y., et al., Visual monitoring of civil infrastructure systems via camera-equipped Unmanned Aerial Vehicles (UAVs): a review of related works. Visualization in Engineering, 2016. 4(1): p. 1-8.

[17] Alizadehsalehi, S., et al., UAS-BIM based Real-time Hazard Identification and Safety Monitoring of Construction Projects, in 9th Nordic Conference on Construction Economics and Organization. 2017: Göteborg, Sweden. p. 22-32.

[18] Holt, E., J. Benham, and B. Bigelow, Emerging Technology in the Construction Industry: Perceptions from Construction Industry Professionals, in 122nd ASEE Annual Conference \& Exposition 2015: Seattle, WA, USA.

[19] Levin, P., Use of Drones in Construction Expected to Increase in 2016, in Design Cost Data 2016, Design Cost Data Construction Magazine California, USA p. 52-53.

[20] Bang, S., H. Kim, and H. Kim, Vision-based 2D map generation for monitoring construction sites using UAV Videos, in 34th International Symposium on Automation and Robotics in Construction. 2017: Taipei, Taiwan.

[21] Liu, P., et al., A review of rotorcraft Unmanned Aerial Vehicle (UAV) developments and applications in civil engineering. Smart Structures and Systems, 2014. 13(6): p. 1065-1094.

[22] Kim, S., et al., Lessons Learned from Unmanned Aerial System-Based 3D Mapping Experiments, in 52nd Annual International Conference of the Associated Schools of Construction. 2016: Utah, USA. p. 1-8.

[23] Tatum, M. and J. Liu, Unmanned Aircraft System Applications In Construction, in Creative Construction Conference 2017. 2017: Primosten, Croatia.
[24] Moon, D., et al., Pre-processing Methodology of Image Compensation using Histogram Equalization for Generating Point-cloud of Construction Environment, in 34th International Symposium on Automation and Robotics in Construction. 2017: Taipei, Taiwan.

[25] Canis, B., Unmanned Aircraft Systems (UAS): Commercial Outlook for a New Industry. 2015, Congressional Research Service Washington, DC, USA.

[26] Ellenberg, A., et al., Use of Unmanned Aerial Vehicle for Quantitative Infrastructure Evaluation. Journal of Infrastructure Systems, 2015. 21(3): p. 1-8.

[27] Hugenholtz, C., et al., Earthwork Volumetrics with an Unmanned Aerial Vehicle and Softcopy Photogrammetry. Journal of Surveying Engineering, 2015. 141(1): p. 1-5.

[28] Agüera-Vega, F., F. Carvajal-Ramírez, and P. Martínez-Carricondo, Accuracy of Digital Surface Models and Orthophotos Derived from Unmanned Aerial Vehicle Photogrammetry. Journal of Surveying Engineering, 2017. 143(2): p. 1-10.

[29] Moser, V., et al., Comparison of different survey methods data accuracy for road design and construction, in 4th International Conference on Road and Rail Infrastructure 2016: Sibenik, Croatia.

[30] Jansen, G., Drone Companies Set Sights on Construction Industry, in AUVSI's Unmanned Systems Mission Critical 2015, The Association for Unmanned Vehicle Systems International VA, USA. p. 20-21.

[31] Choi, S. and E. Kim, Design and Implementation of Vision-based Structural Safety Inspection System using Small Unmanned Aircraft, in Advanced Communication Technology (ICACT). 2015, IEEE: Seoul, South Korea.

[32] Guo, H., Y. Yua, and M. Skitmore, Visualization technology-based construction safety management: A review. Automation in Construction, 2017. 73(January): p. 135-144.

[33] Lattanzi, D. and G. Miller, Review of Robotic Infrastructure Inspection Systems. Journal of Infrastructure Systems, 2017. 23(3): p. 1-16. 